\title{
Recursos per treballar a l’aula la formulació i nomenclatura de química inorgànica
}

\author{
José Ángel Hernández Santadaría (jherna24@xtec.cat) Institut Badalona VII
}

L'article presenta diversos recursos i activitats elaborats per l'autor que permeten treballar la formulació i nomenclatura de química inorgànica a les classes de química d'educació secundària i de batxillerat, seguint les darreres recomanacions de la IUPAC de l'any 2005.

Paraules clau: Química inorgànica, nomenclatura química, IUPAC.

This article sets forth several resources and activities designed by the author which allow the inclusion of formula writing and nomenclature of inorganic chemistry in the chemistry lessons of compulsory secondary education and Baccalaureate, following the latest IUPAC recommendations in 2005.

Keywords: Inorganic chemistry, chemistry nomenclature, IUPAC.

\section{INTRODUCCIÓ}

Els continguts de la matèria de ciències de la naturalesa a $3 r$ d'ESO incorporen el reconeixement dels símbols dels elements més abundants i del significat de les fórmules de les substàncies compostes (1). Entre els continguts de la matèria de química recollits en el decret d'ordenació dels ensenyaments de batxillerat (2), trobem la introducció a la nomenclatura i formulació de les substàncies simples i dels compostos: òxids, hidrurs, hidròxids, àcids i sals.

Les darreres recomanacions de la IUPAC (International Union of Pure and Applied Chemistry) de l'any 2005 sobre nomenclatura sistemàtica inorgànica substitueixen les de 1990 i les seves modificacions de l'any 2000. Malgrat el temps que ha transcorregut des de la publicació de les noves recomanacions, encara no s'ha generalitzat el seu ús i no és habitual trobar-les a les programacions de les classes de química i als llibres de text d'educació secundària i batxillerat.

Donat que en aquests moments no abunden els materials convenientment actualitzats $i$ en llengua catalana per treballar la formulació i nomenclatura inorgànica amb l'alumnat de secundària, l'autor d'aquest article va decidir elaborar diversos recursos $i$ activitats per utilitzar-los durant el primer trimestre del curs 2014-2015 a les seves classes de química de primer de batxillerat. Mitjançant aquest article es vol fer difusió d'aquests materials i compartir-los amb altres docents que els puguin trobar d'utilitat.

\section{DESCRIPCIÓ DELS RECURSOS I LES ACTIVITATS}

\section{Presentació amb un resum de les darreres recomanacions de la IUPAC sobre nomenclatura inorgànica}

El primer material que es descriu és una presentació que recull un resum de les darreres recomanacions sobre nomenclatura sistemàtica inorgànica. La principal referència utilitzada per l'autor en l'elaboració d'aquesta presentació és el treball publicat al maig de 2013 pel Seminari de Química "Del Batxillerat a la Universitat" organitzat per la Direcció General d'Ordenació, Innovació i Formació Professional del Departament d'Ensenyament de la Generalitat de Catalunya, amb l'objectiu de divulgar dins l'àmbit de l'educació secundària les recomanacions de la IUPAC de l'any 2005 (3). 
En aquesta presentació hom pot trobar els continguts següents:

- Nombre d'oxidació

- Nomenclatura dels ions simples

- Nomenclatura de les substàncies elementals

- Nomenclatura dels compostos binaris: òxids, hidrurs, sals i combinacions binàries entre nometalls.

- Nomenclatura dels compostos ternaris: hidròxids, oxoàcids, oxoanions, oxisals i sals àcides.

Seguint la proposta realitzada pel Seminari de Química "Del Batxillerat a la Universitat", pels compostos binaris i els hidròxids s'utilitza la nomenclatura de composició o estequiomètrica amb les seves tres variants: amb prefixos multiplicadors, amb nombres d'oxidació i amb nombres de càrrega per als compostos iònics. Pel que fa als oxoàcids, oxosals i sals àcides s'ha optat per l'ús de la nomenclatura tradicional, acceptada per la IUPAC.
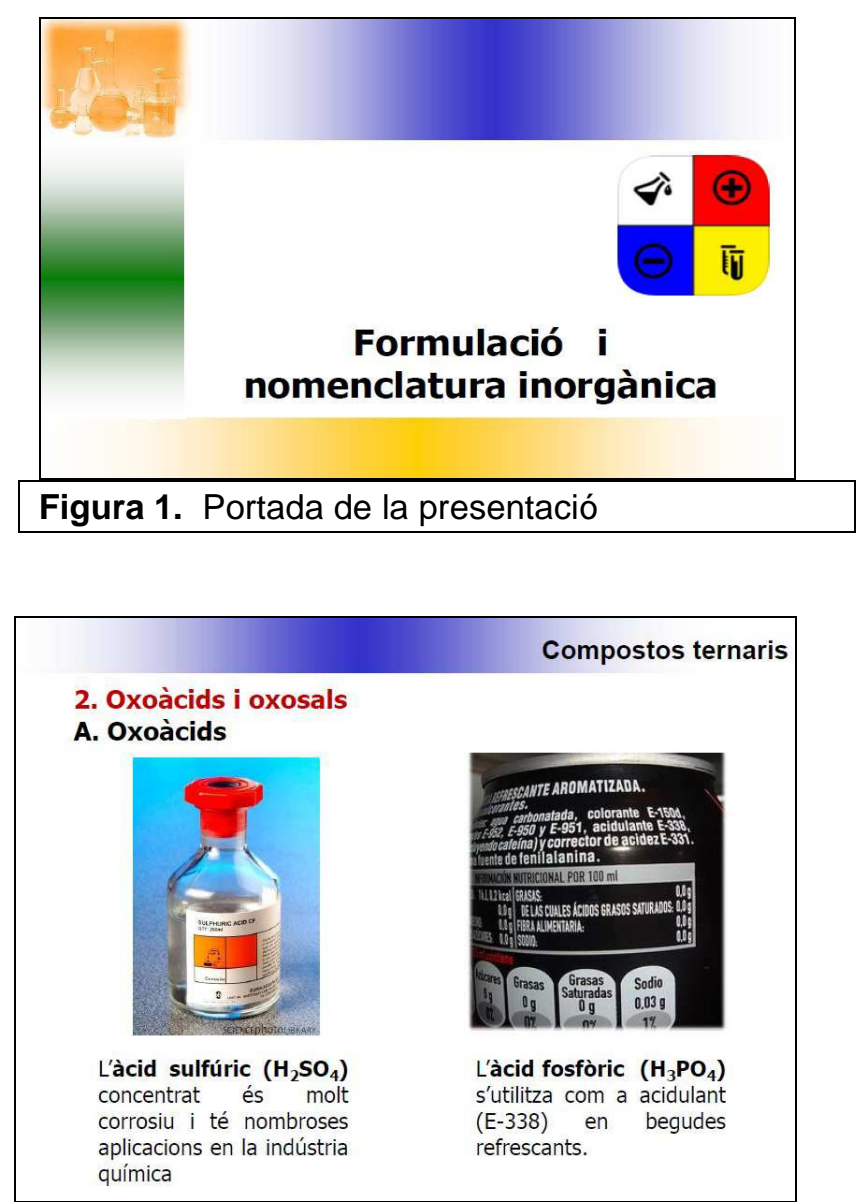

Figura 2. Exemple de diapositiva de la presentació

La presentació, a més de facilitar un resum de les darreres recomanacions de la IUPAC, aporta un bon nombre d'exemples de fórmules i noms sistemàtics de compostos, així com referències a substàncies químiques amb aplicacions a la vida quotidiana o d'importància a nivell industrial.

Aquesta presentació està disponible al portal web Slideshare i és de lliure utilització sota les condicions d'una llicència d'atribució no comercial de Creative Commons (4).

\section{Dossier d'exercicis de formulació i nomenclatura inorgànica}

Com a eina per treballar amb l'alumnat els continguts corresponents a les noves recomanacions de formulació i nomenclatura inorgànica, s'ha elaborat un dossier que recull una col-lecció d'exercicis. L'estructura d'aquest dossier es correspon amb l'índex de la presentació descrita en l'apartat anterior d'aquest article (nombre d'oxidació, nomenclatura dels ions simples, nomenclatura de les substàncies elementals, nomenclatura dels compostos binaris i nomenclatura dels compostos ternaris).

També s'ha elaborat un solucionari que el professor pot projectar a la pissarra digital de l'aula per facilitar la correcció dels exercicis a classe.

Tant el dossier d'exercicis com el solucionari estan penjats a l'aula virtual de química de l'espai Moodle de I'Institut Badalona VII, centre educatiu en el qual treballa actualment l'autor d'aquest article (5).

\section{Exercicis autocorrectius Hot Potato- es}

Hot Potatoes és una aplicació que permet generar de manera senzilla exercicis autocorrectius. El programa és d'ús gratuït per als docents i permet generar sis tipus d'exercicis bàsics: ordenar frases o paraules, qüestionaris de resposta oberta, qüestionaris tipus test, exercicis de relacionar, d'omplir els buits o mots encreuats. Els exercicis creats amb Hot Potatoes es poden incrustar en entorns virtuals d'aprenentatge com Moodle.

Com a activitat de repàs i consolidació dels continguts de formulació i nomenclatura treballats a classe es pot proposar als estudiants la realització d'una bateria d'exercicis autocorrectius. L'autor ha elaborat diversos exercicis amb el programa $\mathrm{Hot}$ Potatoes que es troben a disposició de l'alumnat a través de l'aula virtual de química (5). 


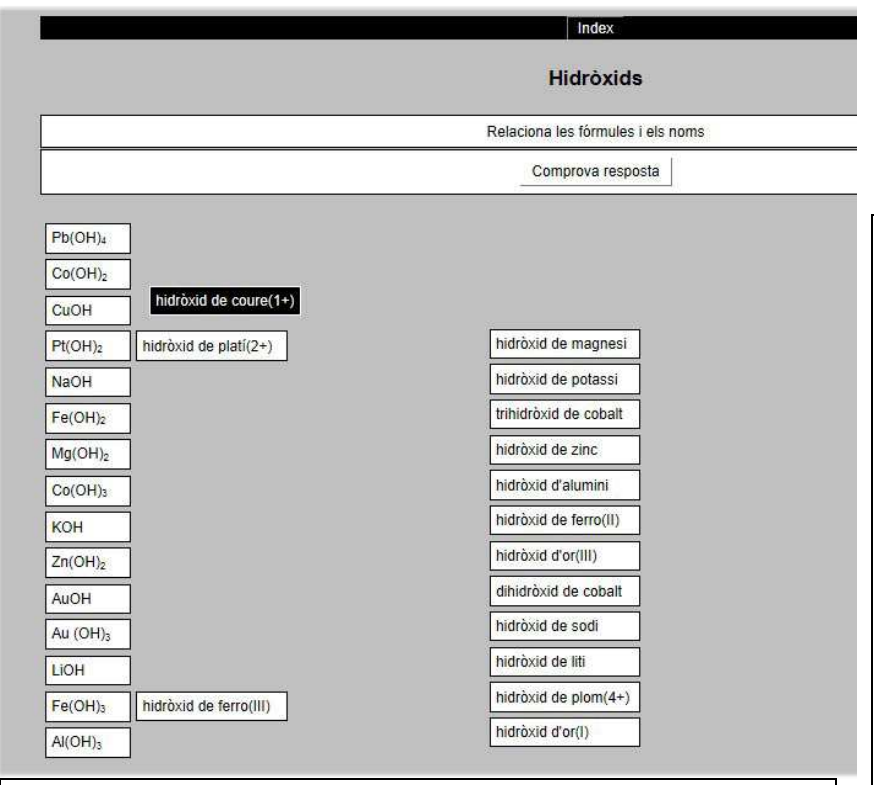

Figura 3. Exercicis autocorrectius Hot Potatoes de nomenclatura inorgànica

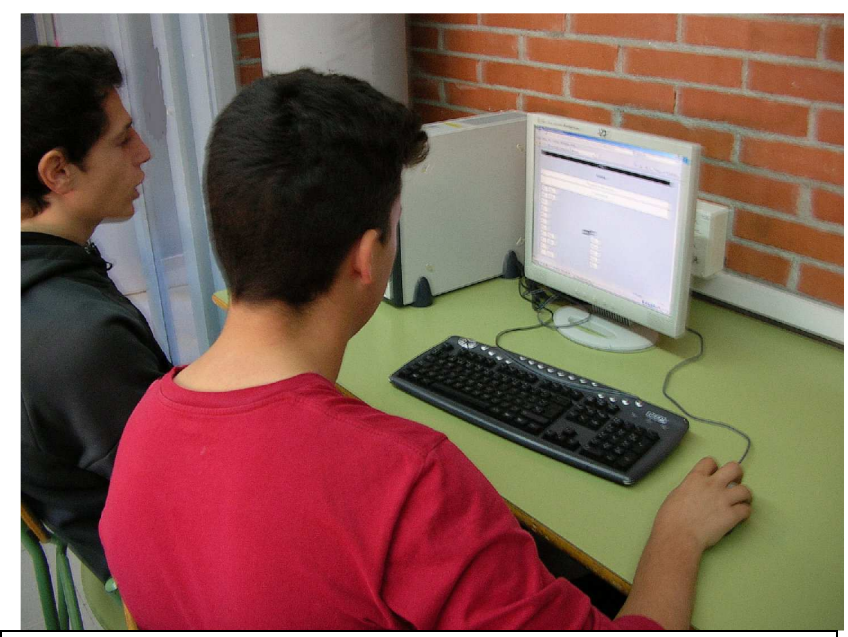

Figura 4. Alumnes realitzant exercicis autocorrectius als ordinadors de l'aula de ciències

\section{Altres materials disponibles a l'aula virtual de química}

A l'aula virtual de química de l'autor es posen a disposició de l'alumnat altres materials, la majoria d'ells elaborats pel professorat del seminari de física i química del centre. Entre aquests materials podem destacar els següents:

- Taula amb el nombre d'oxidació dels elements més freqüents

- Taula amb els noms dels ions més habituals

- Taula amb els oxoàcids i oxoanions més comuns
- Indicacions sobre formulació per a les PAU (Proves d'Accés a la Universitat) de química

- Enllaços a pàgines web amb exercicis autocorrectius

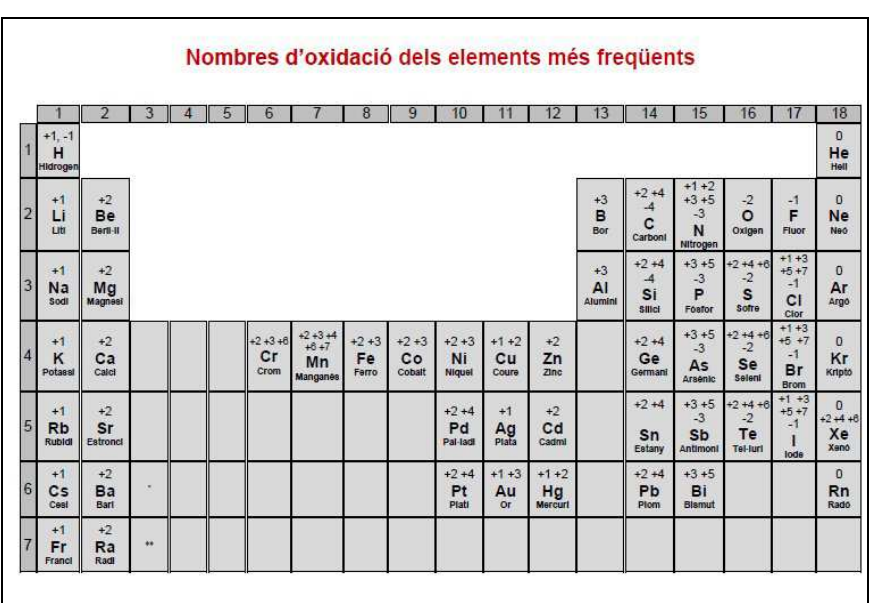

Figura 5. Taula amb els nombres d'oxidació dels elements més freqüents elaborada pel seminari de física i química de l'Institut Badalona VII

\section{VALORACIONS}

- Els materials presentats en aquest article han estat dissenyats per la seva aplicació a les classes de primer de batxillerat però, amb petites modificacions, es podrien utilitzar també amb l'alumnat de $3 \mathrm{r}$ o $4 \mathrm{t}$ d'ESO.

- Una vegada aplicats a l'aula a principis del curs 2014-2015, els materials han obtingut una bona valoració per part dels estudiants que els han trobat entenedors i pràctics.

- En els registres d'avaluació realitzats una vegada finalitzada la unitat didàctica dedicada a la formulació i la nomenclatura inorgànica, la majoria dels alumnes han obtingut un resultats positius, aprovant 27 dels 29 alumnes del grup (93\%).

\section{REFERÈNCIES}

(1) Currículum d'educació secundària obligatòria. Decret 143/2007 (DOGC núm. 4915)

(2) Currículum de batxillerat. Decret 142/2008 de 29 de juliol (DOGC núm. 5183)

(3) Nomenclatura química inorgànica, recomanacions IUPAC 2005. Treball elaborat pel Seminari de Química (Del Batxillerat a la Universitat) organitzat per la Direcció General d'Ordenació, Innovació i Formació Professional (2013). Disponible en línia:

http://estudis.uib.cat/digitalAssets/257/257448_5no menclatura_iupac.pdf. 
(4) Presentació amb un resum de les darreres recomanacions de la IUPAC sobre nomenclatura de química inorgànica

http://www.slideshare.net/joseangelb7/formulacioinorgnica/
(5) Aula virtual de química de l'autor:

http://agora.xtec.cat/iesb7/moodle/course/view.php ?id $=642$

[L'última data de consulta de tots els enllaços és el 17 de novembre de 2014.] 